\title{
Lean Practices for Product and Process Improvement: Involvement and Knowledge Capture
}

\author{
Jannis J. Angelis ${ }^{1}$ and Bruno Fernandes ${ }^{2}$ \\ 1 Warwick Business School, University of Warwick, Coventry CV4 7AL, \\ UK, jannis.angelis@wbs.ac.uk \\ 2 Centro Universitario Positivo, Curitiba 81280 Brazil, bruno@unicenp.br
}

\begin{abstract}
Innovation is key source of a company's competitiveness in the knowledge economy, and continuous improvement is a key element of such corporate pursuit. Lean production is a globally competitive standard for product assembly of discreet parts. Successful Lean application is conditioned by an evolutionary problem-solving ability of the rank and file. Such ability is in itself contingent on employee involvement in improvement programs and the implementation of appropriate practices. But the challenge of operating innovative Lean systems lacks statistically valid guidance. This empirical study is based on 294 worker responses from twelve manufacturing sites in four Brazilian industry sectors. It identifies particular practices that impact employee participation in change or improvement activities and their performance outcomes.
\end{abstract}

\section{Keywords}

Lean Operations, continuous improvement, worker involvement

\section{Introduction}

As described by Lewis Carroll in Through the Looking Glass, today's businesses can be described as operating in a Red Queen economy, where it takes all the running you can do, to keep in the same place. Innovation is key source of competitiveness in the knowledge economy [1]. Continuous improvement (CI) is a core element of such corporate pursuit $[2,3]$ and can be summarized as a company-wide focus to improve process performance [4]; using gradual step by step improvement $[5,6]$ ) and organizational activities with the involvement of all people in the company $[4,7]$, while creating a learning and growing environment [8]. Lillrank and Kano [9] refer 
to $\mathrm{Cl}$, or kaizen as the "principle of improvement". $\mathrm{Cl}$ programs were initially developed in organizations with product-focused processes or repetitive processes [10]. Special teams were organized to work on improvement tasks, which were separate from their typical organizational tasks. As such, through their commitment and involvement employees become a source of sustainable competitive advantage. $\mathrm{CI}$ activities are a core philosophy in Lean operations as a means of improving product quality and reducing waste throughout the operations. [11]. Lean, if applied correctly, results in the ability of an organization to learn. Lean operates with balanced, synchronised material flow and minimum use of 'wasteful' contingencies of material, people and machinery. While there is literature on workforce effects of Lean [12-15], this study focuses on involvement. Lauder [16] links the 'high performance work organisation' with Lean, whereby a 'degree of power is devolved to teams to engage in a constant process of innovation and improvement'. Womack et al. [17] advocate that involved workers are necessary for the expanded roles effective CI program require, and that the worker involvement is enhanced by job enrichment such as improvement projects, self-inspecting tasks, and conducting routine maintenance. Contrary, Delbridge and Turnbull [18] and Bruno and Jordan [19] argue that Lean implementation may diminish worker commitment through fastpaced, high intensity operations with close monitoring, de-skilling and little job autonomy.

The Brazilian industrial complex has been built up over the last century through a combination of private, state-owned and multinational firms, and through joint ventures between them with an industrialisation pattern similar to Mexico, Argentina and Chile [20-23], Hungary and Bulgaria [24], India and China [25]. Moreover, Brazil has been considered a training "lab" for uncertainty and unfavourable conditions, where quality and productivity issues are being considered from the perspective of a globalised economy as a way for reducing costs and cycle times as well as improving sales and profits [26, 27]. Lean has been implemented across Brazil with little unions or worker resistance $[28,29]$. While efforts have been made to implement a local Lean version, a Brazilian system has not emerged [30].

\section{Method}

Conti and Gill [31] developed the initial hypotheses by examining expected outcomes for a variety of Lean practices. The independent variables were twenty-one lean work practices and thirteen control variables recorded on five-point Likert scales. Several authors [32-34] argue that product and process innovations need to be separate in studies of $\mathrm{CI}$, since they not necessarily share determinants. Hence, the dependant variables consist of worker suggestions to improve existing products and processes. Avoiding an object approach (i.e. innovation count) also reduces the favour of radical innovations over incremental ones and product over process innovations [35]. The independent lean implementation variable was measured using ten key elements: set-up reduction, Inventory and waste reduction, kanbans, supplier partnerships, continuous improvement program, mixed-model production, total quality management, Foolproof or design-for-assembly, total preventive 
maintenance, and standard operating procedures. Scale reliability, measured by the Cronbach alpha, was .816 . Their levels were estimated on a five-point scale in the management questionnaire, using categories of Powell [36]. Plant tours and interviews helped to verify management responses. The sampling plan of Cook and Campbell [37] was used to recruit sites differing in work practices. Sample space is the population of Brazilian sites with 60 or more assemblers. All 12 sites are in four US SICs: three in 35 (machinery), three in 36 (appliances and electronics), three in 37 (motor vehicles) and three in 38 (instruments), similar to the distribution reported by Fullerton et al. [38]. Sites are a mix of union and non-union workplaces. All assemblers received instructions and were given questionnaires in stamped envelopes for anonymous posting. 294 questionnaire responses were obtained out of 840 , generating a response rate of $35 \%$.

\section{Analysis of work practices and improvement}

Continuous improvement through worker participation is a core lean principle. The study results reveal that there is a significant correlation between lean implementation and product and process suggestions $(\mathrm{r}=520, \mathrm{p}<.001)$, as well as their implementation (respectively $r=582, p<.001$ and $r=418, p<.001$ ). Analysis of Variance was used to check the means and $95 \%$ confidence intervals for the five levels of affective commitment responses. Multiple regression, using redefined variables, identified relationships significant at .05 or less. The work practice hypotheses were tested using stepwise regression, with product and process suggestions as response variables. The former model $F=7.281, p<.001$, adjusted $R$ square .041 , and the latter is $F=5.911, \mathrm{p}<.001$, adjusted $\mathrm{R} .063$. There is no evidence of collinearity, with VIF values well below the usual cut-off of 10 .

Description, beta coefficient and significance level is given for each work practice with an association as measured by the standardized coefficients significant at .05 or less. As for control variables, there were no significant relationships for age or years of employment at the site, or for perceived job security. It appears that demographic and life-style factors do not materiaily affect the study results.

Lack of tools The relationship between process suggestions and the lack of proper tools is significant and positive. (Beta $=.132, \mathrm{p}=.026$ ). The lack of appropriate tools indicates inadequate technical support, and can also lead to quality problems, and raises managerial competence issues .

Work pace and intensity The significant and positive relationship between pace and intensity and worker suggestions on process improvements $(B e t a=.162, p=.005)$ fits the lean notion of employing resource removal as a change catalyst [39]. But a high pace and intensity may also be perceived as 'unfair' and hence erode worker commitment.

Flow interruptions The relationship between process suggestions and flow interruptions is significant and positive. (Beta $=.129, \mathrm{p}=.031)$. Flow interruptions have mixed worker effects. The broken repetition may relieve task monotony, but may also interrupt the steady rhythm of job task that many workers value [17]. Nonetheless, flow interruptions are beneficial in that they may provide workers with 
more time to think about existing processes, or that workers' dislike for interruptions galvanize them into making improvement suggestions.

Team work The relationship between process suggestions and the utilisation of team work is significant and positive. (Beta $=.117, \mathrm{p}=.041$ ). Support from peers or supervisors is not significant. Team work allows for worker job task expansion and supports peer support for time and quality standards, and it also indicates management confidence in workers' ability to multi-task. Nonetheless, given some workers preference for working alone, it may be prudent to offer alternative choices.

Feeling of being blamed for defects There is a negative association between product suggestions and the feeling of being blamed for defects. (Beta=-.171, $\mathrm{p}=.003$ ). Lean pinpoints specific defect locations which may make individual workers feel they are being blamed. Moreover, blame feelings persist long after actual defect episodes, perhaps due to lingering apprehension about future defects. For successful employee involvement, workers must be given the opportunity and responsibility for organizational change and improvement, but they must also be motivated to avail themselves of this opportunity and responsibility.

Working longer hours than desired There is a positive association between product suggestions and working longer hours than desired. (Beta $=.153, p=.008$ ). It may indicate the undesired overtime intrusion into private life that hampers worker commitment, and in turn involvement in improvement schemes.

Martinez-Ros [40] found that product and process innovations are interdependent. Neglecting process innovations can weaken firm capacity to develop new products, and undermine the innovation process entirely. The research results indicate the prevalence of three conditions. First, working conditions perceived to be harsh or difficult appear to motive workers to make (process) suggestions, as seen by the significant variables of lack of appropriate tools, high pace and intensity, and flow interruptions. The study results shows that worker commitment is significant for suggestions made on products (Beta $=.171, \mathrm{p}=.003$ ) but insignificant for process suggestions. This make sense, since a committed worker may have an interest in improving the product, while a non-committed worker may primarily be motivated to improve his or her immediate working conditions. Second, supportive work practices in the form of mutually beneficial human resource practices and industrial relations, such as team work, a flexible work schedule, and the absence of a blame culture strengthen worker improvement involvement. Third, poorly designed or implemented processes may make them easy improvement targets for the workers an improvement form of low hanging fruit.

As Midgley [41] points out, there is limited advantage in developing worker commitment and involvement if there then is no commitment on the part of the management to provide the environment in which the workers' involvement can be applied. The relationship between workers making improvement suggestions on existing products or processes and worker participation in formal improvement schemes is not significant. Hence, formal participation in improvement exercises is not necessarily a good indication of worker involvement. Similarly, on a firm level, there appears to be weak links between a formal innovation strategy and actual worker involvement on the shop floor. This gap indicates poor management by-in to improvement through worker involvement [41].

Ergonomics The relationship between ergonomics and implemented process 
suggestions (Beta $=-.218, \mathrm{p}<.001)$ and product suggestions (Beta $=-.163, \mathrm{p}=.006$ ) is significant and negative. Positioning hard to handle items shows lack of technical support. Indirectly poor ergonomics restricts access to physically demanding jobs, and in turn fail to capture all potential innovators [42].

Comments on change The relationship between implemented process suggestions and comments on change is significant and positive. (Beta $=.169, p=.003$ ). Similarly, the relationship between implemented product suggestions and comments on change is significant and positive. (Beta $=.132, p=.020$ ). Such capture of suggestions indicates good management practice.

Pace control The relationship between implemented process suggestions and pace control is significant and positive. (Beta $=.161, \mathrm{p}=.004$ ).

Blame for defects There is a negative association between implemented product suggestions and the feeling of being blamed for defects. (Beta $=-.158, p=.006$ ).

$J o b$ rotation The relationship between implemented product suggestions and job rotation is significant and positive. (Beta $=.163, \mathrm{p}=.005$ ). Task expansion, as well as greater co-worker interaction, may lead to better suggestions through improved shared understanding.

Change autonomy The relationship between implemented product suggestions and worker change autonomy is significant and positive. (Beta=.131, $\mathrm{p}=.021$ ). Danford [43] notes that job autonomy, rather than team working, can have a positive impact on workers' sense of trust, commitment and satisfaction. But to reduce the likelihood of errors induced due to human error probability, enhancement of worker autonomy must at the same time limited discretion [44]. Complexity can be minimised through product and assembly design, while variability can be minimised through poka-yoke systems and non-discretionary tasks.

The results indicate that managers should pursue employee involvement rather than intensification approach [45]. Berggren [13] calls this a team rather than JITdriven lean approach, achieving gains through high employee commitment rather than through cost reduction and work intensification.

There is a strong and positive correlation between productivity and quality $(r=.947, p<0.001)$ and delivery $(r=.993 \mathrm{p}<0.001)$, and between delivery and quality $(.996 \mathrm{p}<0.001)$. Following the Sandcone model, operational advantage is based on high product quality. There is a positive and significant association between product improvement suggestions and product quality $(r=.187, p=.013)$ and there is a positive and significant association between process improvement suggestions and speed of delivery $(r=.210, p=.005)$. But there are no other significant relationships between product and process improvement suggestions and realised improvements in quality, productivity or delivery. Perhaps unsurprising, speedy introduction of new products appears to have a negative effect on improvement suggestions from the workforce $(\mathrm{r}=-.176, \mathrm{p}=.020$ and $\mathrm{r}=-.201, \mathrm{p}=.008$ for product and process suggestions respectively). Similarly, the relationship to implemented process improvements is significant and negative $(r=-.270, P<.001)$. There is a significant and positive relationship between the implementation of suggestions on process improvements and manufacturing unit cost $(\mathrm{r}=.152, \mathrm{p}=.044)$, ability to change product mix ( $\mathrm{r}=.207$, $\mathrm{p}=.006)$ and speed of delivery $(\mathrm{r}=.350, \mathrm{p}<.001)$. Appelbaum et al. [46] and Pil and MacDuffie [47] state that high involvement practices employ workers in improvements activities to improve quality and not to achieve cost reductions. The 
results show that worker suggestions on process improvements mainly have an impact on product quality $(r=.157, p=.008)$, which indicates that the involvement aspect on Lean may fit into the same category. This shows both the importance of tracking implementation of suggestions and the use of appropriate product design and process design other than on the shop floor. For instance, product improvements can be pursued through dedicated design teams while workers on the shop floor focus their suggestions to error proofing activities. This has the benefit of reducing the probability of human error and reducing discretion while at the same time retaining a degree of job autonomy and capturing employee skills and knowledge.

\section{Conclusion}

The results show that there is a significant correlation between lean implementation and product and process suggestions and their implementation, even when controlling for firm size or age, unionized workforce and compensation systems. The statistical analysis of particular work practices and their relationship with product and process suggestions made by individual workers or teams reveals that process suggestions are driven by a combination of difficult working conditions that the workers seek to improve and team-based work. However, for suggestions on product improvements significant practices are worker favourable industrial relations and human resource practices. In terms of implementation of suggestions, both product and process suggestions are significantly and positively correlated with management capturing ideas voiced by the workers, worker discretion in pace and task, and job rotation. To control for human error probability and ensure product quality and consistency, a degree of job autonomy may be needed but adverse effects of job discretion on product quality need to be built out through poka-yoke fool-proofing designs. The results also indicate that the main direct business benefit is in enhanced product quality through process, rather than product, improvements. This suggests that management should pursue worker involvement on continuous process improvements, and employ designated design teams for product improvements. For the unfavourable practices, actions should minimise their negative effects. First, if possible, overtime should be voluntary, aided by cross-training of workers to expand the pool of volunteers. Second, task time standards should be set with pace and intensity set at 'normal' levels as defined by industrial practice. Third, process designs should emphasise eliminating ergonomic difficulties, providing adequate tools and minimising flow interruptions. Finally, supervisory training and disciplinary policies must emphasise "blame free" defect investigations.

\section{References}

1 G. Hulta, G., Hurleyb, R. and Knight, R., Innovativeness, Industrial Marketing Management, 33, 429-438 (2004).

2 R. Cooper, From Experience: the invisible success factors in product innovation, Journal of Product Innovation Management", 16, 115-133 (1999). 
$3 \mathrm{C}$. Wu and $\mathrm{C}$. Chen, An integrated structural model towards successful continuous improvement activity, Technovation, 20, 1-11 (2005).

4. M. Imai, Kaizen: the Key to Japan's Competitive Success (Random House, NY, 1986).

5. C. Berling, Continuous improvement as seen from groups and improvement agents, Total Quality Management, 11(4-6), 484-489 (2000).

6. A. Brunet and S. New, Kaizen in Japan, International Journal of Operations and Production Management, 23 (12), 1426-1446 (2003).

7. J. Bessant and S. Caffyn, High involvement innovation through continuous improvement, International Journal of Technology Management, 14(1), 7-28 (1997)

8. R. Delbridge and H. Barton, Organizing for continuous improvement, International Journal of Operations and Production Management, 22(6), 680-692 (2002).

9. P. Lillrank and N. Kano, Continuous Improvement, Center for Japanese Studies, University of Michigan, Ann Arbor, MI. (1989).

10. N. Bhuiyan and A. Baghel, An overview of continuous improvement, Management Decision, 43(5), 761-771 (2005).

11. C. Forza, Work organization in lean production and traditional plants, International Journal of Operations and Production Management, 16(2), 42-62 (1996).

12 S. Kamata, Japan in the Passing Lane (Allen and Unwin, London, 1983).

13. C. Berggren, Lean production, Work, Employment and Society, 7, 163-188 (1993).

14. R. Conti, J. J. Angelis, C. Cooper, B. Faragher and C .Gill, Lean production implementation and worker job stress, International Journal of Operations and Production Management, 26(9), 1013-1038 (2006).

15. J J. Angelis, R. Conti, C. Cooper and C. Gill, Building a high commitment lean production culture, Working Paper, Institute for Manufacturing, University of Cambridge (2006).

16. H. Lauder, Innovation, skill diffusion, and social exclusion in P. Brown, A. Green and H. Lauder (eds.) High Skills (Oxford University Press, Oxford,2001), pp. 161-203.

17. J. Womack, D. Jones and D. Roos, D. The machine that changed the world (New York: Rawson Associates, 1990).

18. R. Delbridge and P. Turnbull, Human resource maximisation, in P. Blyton and P. Turnbull (eds), Reassessing Human Resource Management (Sage, Newbury Park, 1992).

19. R. Bruno and L. Jordan, Lean production and the discourse of dissent, Working USA, 6(1), 108-134 (2002).

20. M. Bertin, A view of quality trends in South America in the twenty-first century, The TQM Magazine, 11(6), 409-413 (1999).

21. A. Fleury, The changing pattern of operations management in developing countries, International Journal of Operations and Production Management, 19(5/6), 552-564 (1999).

22. B. Flores, F. Burgos and A. Marcias, Manufacturing practices in Mexico, in D. Whybark and G. Vastag (Eds), Global Manufacturing Practices, (Elsevier, Amsterdam, 1993).

23. A. Kovacevic, C. Lopez and C. Whybark, Manufacturing practices in Chile, in D. Whybark and G.Vastag (Eds), Global Manufacturing Practices (Elsevier, Amsterdam, 1993).

24. A. Chikan and K. Demeter, Manufacturing strategies in Hungarian industry, International Journal of Operations and Production Management, 15(11), 5-19 (1995).

25. A. Fleury and M. Fleury, Competitive strategies and core competencies, Integrated Manufacturing Systems, 14(1), 16-25 (2003).

26. L. Carpinetti, F. Santos and M. Gonçalves, Human resources and total quality management, The TQM Magazine, 10(2), 109-114 (1998). 
27. C. Lemos, Innovation and industrial policies for small firms in Brazil, 4th International Conference on Technology Policy and Innovation, Curitiba, 28-31 August (2000).

28. J. Humphrey, Japanese production management and labour relations in Brazil, Journal of Development Studies, 30(1), 92-114 (1993).

29. T. Wallace, Innovation and hybridization, International Journal of Operations and Production Management, 24(8), 801-819 (2004).

30. S. Pires, New productive systems in the auto industry, GERPISA 11th colloquium, Palais de Luxembourg, Paris, June 7-9 (2001).

31. R. Conti and C. Gill, Hypothesis creation and modelling in studies, International Journal of Employment Studies, 6(1), 149-173 (1998).

32. N. Becheikh, R. Landry and N. Amara, Lessons from innovation empirical studies in the manufacturing sector, Technovation, 10, 1-21 (2005).

33. J. Linder, S. Jarvenpaa, and T. Davenport, Toward an innovation sourcing strategy, MIT Sloan Management Review, summer, 43-49 (2003).

34. J. Michie, and M. Sheehan, Labour market deregulation, 'flexibility' and innovation, Cambridge Journal of Economics, 27(1), 123-143 (2003).

35. M. Flor and M. Oltra, Identification of innovating firms through technological innovation indicators, Research Policy, 33, 323-336 (2004).

36. T. Powell, Total quality management as competitive advantage, Strategic Management Journal, 16, 15-37 (1995).

37. C. Cook and R. Campbell, Quasi-Experimentation (Houghton and Mifflin, Boston, 1979).

38. R. Fullerton, C. McWatters and C. Fawson, An examination of the relationships between JIT and financial performance, Journal of Operations Management, 21, 383-404(2003).

39. D. Buchanan, Cellular manufacturing and the role of teams, in J. Storey (ed), New Wave Manufacturing Strategy (Paul Chapman, London, 1994).

40. E. Martinez-Ros, Explaining the decisions to carry out product and process innovations, The Journal of High Technology Management Research, 10(2), 223-242 (1999).

41. D. Midgley, How can Australia improve?, Enterprising Nation, Canberra, AGPS (1995).

42. P. Adler, B. Goldoftas and D. Levine, Ergonomics, employee involvement, and the Toyota production System, Industrial \& Labor Relations Review, 50(3), 416-435 (1997).

43 A. Danford, Workers, unions and the high performance workplace, Work, Employment and Society, 17(3), 569-573 (2003).

44. R. Conti and M. Warner, Technology, culture and craft, New Technology, Work and Employment, 12(2), 123-135 (1997).

45. H. Shaiken, S. Lopez and I. Mankita, Two routes to team production: Saturn and Chrysler compared, Industrial Relations, 36, 17-46 (1997).

46. E. Appelbaum, T. Bailey, P. Berg and A. Kalleberg, Manufacturing Advantage (Cornell University Press, Ithaca, 2000)

47. F. Pil and J. MacDuffie, The adoption of high-involvement work practices, Industrial Relations 35(3), 423-455(1996). 